\title{
Estimating pesticides in public drinking water at the household level in Denmark
}

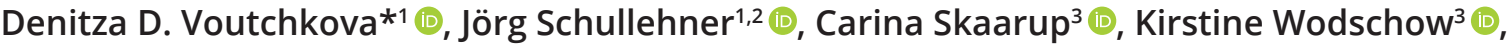 \\ Annette Kjær Ersbø|l ${ }^{(0)}$, Birgitte Hansen ${ }^{1}$ (i)
}

'Geological Survey of Denmark and Greenland (GEUS), Aarhus, Denmark, ${ }^{2}$ Department of Public Health, Research Unit for Environment, Work and Health, Aarhus University, Aarhus, Denmark, ${ }^{3}$ National Institute of Public Health, University of Southern Denmark, Copenhagen, Denmark

\begin{abstract}
Pesticide pollution has raised public concern in Denmark due to potential negative health impacts and frequent findings of new substances after a recent expansion of the groundwater monitoring programme. Danish drinking water comes entirely from groundwater. Both the raw groundwater and the treated drinking water are regularly monitored, and the chemical analyses are reported to a publicly available national database (Jupiter). Based on these data, in this study we (1) provide a status of pesticide content in drinking water supplied by public waterworks in Denmark and (2) assess the proportion of Danish households exposed to pesticides from drinking water. 'Pesticides' here refers also to their metabolites, degradation and reaction products. The cleaned dataset represents 3004 public waterworks distributed throughout the country and includes 39798 samples of treated drinking water analysed for 449 pesticides (971 723 analyses total) for the period 2002-2019. Of all these chemical analyses, $0.5 \%(n=4925)$ contained a quantified pesticide $(>0.03 \mu \mathrm{g} / \mathrm{l})$. Pesticides were found at least once in the treated drinking water at $29 \%$ of all sampled public waterworks for the period 2002-2019 and at 21\% of the waterworks for the recent period 2015-2019. We estimate that 56\% of all Danish households were potentially exposed at least once to pesticides in drinking water at concentrations of 0.03-4.00 $\mu \mathrm{g} / \mathrm{l}$ between 2002 and 2019. However, in 2015-2019, the proportion of the Danish households exposed to pesticides $(0.03-4.00 \mu \mathrm{g} / \mathrm{l})$ was $41 \%$. The proportion of Danish households potentially exposed at least once to pesticides above the maximum allowed concentration $(0.1 \mu \mathrm{g} / \mathrm{l})$ according to the EU Drinking Water Directive (and the Danish drinking water standard) was $19 \%$ for $2002-2019$ and $11 \%$ for $2015-2019$. However, the maximum concentrations were lower than the World Health Organization's compound-specific guidelines. Lastly, we explore data complexity and discuss the limitations imposed by data heterogeneity to facilitate future epidemiological studies.
\end{abstract}

\section{Introduction}

Pesticides are biologically active compounds widely used in agriculture, horticulture and public health for the control of pests (World Health Organization 2019a). They comprise many chemical substances with a broad variety of mode of action depending on their target organisms (Casida 2009), for example, photosynthesis inhibition (plants), neurotoxic (insects) and fungal spore

\author{
*Correspondence: dv@geus.dk \\ Received: 24 Nov 2020 \\ Accepted: 10 Feb 2021 \\ Published: 12 Apr 2021
}

Keywords: Denmark, drinking water, exposure, pesticides, public waterworks

\section{Abbreviations \\ BAM: 2,6-Dichlorobenzamide DBCP: Dibromochloropropane DEIA: Desethyl-desisopropyl atrazine DPC: Desphenyl chloridazon DMS: N,N-dimethylsulfamide DDT: Dichlorodiphenyltrichloroethane DWD: Drinking Water Directive DWQS: Drinking water quality standard EPA: Environmental Protection Agency GEUS: Geological Survey of Denmark and Greenland MDPC: Methyl-desphenyl-chloridazon LOD: Limit of detection LOQ: Limit of quantification WHO: World Health Organization WSA: Water supply area}

GEUS Bulletin is an open access, peerreviewed journal published by the Geological Survey of Denmark and Greenland (GEUS). This article is distributed under a CC-BY 4.0 licence, permitting free redistribution, and reproduction for any purpose, even commercial, provided proper citation of the original work. Author(s) retain copyright.

Edited by: Adam Hambly (Technical University of Denmark)

Reviewed by: Martin Rygaard (Technical University of Denmark), Kai Tang (Technical University of Denmark)

Funding: See page 14

Author contributions: See page 14

Competing interests: None declared

Additional files: See page 15 
inhibition (fungi). For a classification of over 180 active substances (pesticides) and their metabolites based on the mode of action, see Mohaupt et al. (2020; Annex 5). Agricultural pesticides threaten aquatic biodiversity (Stehle \& Schulz 2015) and potentially impact food-webs and species competition (Kohler \& Triebskorn 2013).

New pesticides are registered for use only if they are demonstrated not to persist in the environment after their intended period of use. However, residues are found in the natural environment in nanogram to microgram per litre levels (Fenner et al. 2013). For example, the status assessments for water bodies in the European Environmental Agency countries showed that $0.4 \%$ of all surface water bodies and $6.5 \%$ of the area of groundwater bodies are failing 'good chemical status' because of pesticides (Mohaupt et al. 2020). In fact, pesticides are second only to nitrates as a cause for failing to achieve a level of good chemical status in Europe (Mohaupt et al. 2020). This shows that pesticides persist in the environment, and the only natural removal is through degradation by biotic or abiotic transformation processes (Fenner et al. 2013).

\subsection{Pesticide exposure and drinking water}

Pesticides are inherently hazardous compounds, but even though only a small fraction is highly hazardous (World Health Organization 2019b), they cause disproportionate harm to the environment and human health worldwide (Food and Agriculture Organization \& World Health Organization 2019). The greatest human exposure to pesticides occurs in occupational environments, for example, in factory, agricultural and public health workers during production, handling, dilution, mixing and application procedures (World Health Organization 2019a). Acute pesticide poisoning is an important cause of mortality and morbidity, for example, due to neurotoxic effects of organophosphate intoxication (Rosenstock 1991). However, there is incomplete knowledge on the toxicity of the metabolites, degradation and reaction products, which could have a similar, stronger or lesser effect on organisms and humans (Mohaupt et al. 2020; p. 7, Box 1).

The general population may be environmentally exposed to pesticide residues from food and drinking water (World Health Organization 2019a). A variety of chronic health effects related to exposure at doses that do not cause acute effects have been suggested, including asthma, diabetes, Parkinson's disease and cancer (Kim et al. 2017). Protecting the population from health risks associated with pesticide-contaminated drinking water is a worldwide problem (Li \& Jennings 2018). Thirty-four percent of the world's population, in $>1 / 2$ of the world's nations, are estimated to be inadequately protected against health risks associated with pesticide-contaminated drinking water (Li \& Jennings 2018). Pesticide pollution was recently found to be of major concern in drinking water sources in the Netherlands, where pesticides were found in 2/3 of the water abstraction areas. The water-quality standard was exceeded in 1/3 of all drinking-water sources in the Netherlands (including both groundwater and surface-water bodies; Sjerps et al. 2019). Bexfield et al. (2021) also showed that at least one pesticide or degradate was found in $41 \%$ of wells investigated in the United States $(n=12041204$ in aquifers responsible for $70 \%$ of the volume pumped for public drinking-water supply, nationally), and around $2 / 3$ of them contained compound mixtures. Although pesticide compounds occurred frequently, concentrations were low, and only $1.6 \%$ of wells had concentrations approaching levels of potential health concern (Bexfield et al. 2021).

Pesticide exposure from drinking water in Denmark is estimated to be smaller than that from other dietary sources, such as berries, fruits and vegetables (Bichel hovedudvalget 1999). Nevertheless, concerns about adverse health outcomes due to long-term low-dose intake from drinking water have been raised, and there has not been enough scientific evidence to either support or reject potential health risks (Bichel hovedudvalget 1999). While the pesticides found in food products are mainly contemporary insecticides and fungicides (approved for use), the pesticides found in drinking water are mainly herbicides, often representing legacy pollution. The term 'pesticide' covers a large group of substances with different structure and mechanism of action, making it relevant to study the presence and potential influence of pesticides in drinking water. To the best of our knowledge, there are no recent publications on drinking water as a dietary source of pesticides in Denmark. Exposure estimates from drinking water in Denmark are thus lacking.

\subsection{Objectives}

The purpose of this article is (1) to assess the pesticide status of Danish drinking water, (2) to estimate the population's exposure to pesticides from drinking water and (3) to evaluate the dataset heterogeneity and limitations. We take advantage of the national database Jupiter; https://eng.geus.dk/products-services-facilities/data-andmaps/national-well-database-jupiter) in which all drinking water samples taken for compliance or other purposes are centrally registered. The study period is 18 years (2002-2019) with sufficient data coverage to analyse the current drinking water status at a national level for the entire study period and specifically, the last five years (2015-2019). 


\section{Study setting and legal framework}

European Union member states must ensure that water intended for human consumption is 'wholesome and clean', according to the Drinking Water Directive (DWD; Council of the European Union 2015). This means that drinking water should comply with the DWD's minimum requirements for several microbiological and chemical components, including pesticides. The maximum allowed concentration of pesticides in drinking water - the drinking water quality standard (DWQS) - is set in the DWD at (1) $0.10 \mu \mathrm{g} / \mathrm{l}$ for individual compounds, except for aldrin, dieldrin, heptachlor and heptachlor epoxide, which are set at $0.030 \mu \mathrm{g} / \mathrm{l}$, and (2) $0.50 \mu \mathrm{g} / \mathrm{l}$ for the sum of detected and quantified pesticides (named 'Pesticides - Total' in the DWD). The DWD also provides a legal definition of the term 'pesticide', which we follow in this article:

'Pesticides means [-] organic insecticides, [-] organic herbicides, [-] organic fungicides, [-] organic nematocides, [-] organic acaricides, [-] organic algicides, [-] organic rodenticides, [-] organic slimicides, [-] related products (inter alia, growth regulators) and their relevant metabolites, degradation and reaction products'. (Annex I, Part B, Note 6 of the DWD; the square brackets indicate a change in the punctuation from the original DWD)

Denmark has implemented the DWD provisions in national legislation (Vandforsyningsloven; LBK $\mathrm{nr} 118$, 22 February 2018). Actionable items (e.g. sampling frequencies and DWQS) are further specified by Ministerial Orders (the most recent is BEK nr 1070, 28 October 2019). The frequency of sampling varies based on the volumes of drinking water produced, from once every 3 years to several times per year (BEK nr 1070, 28 October 2019). The list of compounds monitored for mandatory compliance is revised every year, and currently, it contains 46 pesticides. Waterworks must also test for other pesticides if there is evidence that their presence in the catchment area poses a health threat.

Danish drinking water supply is decentralised $(>4500$ public waterworks) and $100 \%$ groundwater based. It mostly relies on simple groundwater treatment, including aeration and sand filtration. If the simple treatment is not sufficient to assure compliance with the DWQS, the municipalities can grant permits for the use of advanced treatment processes. In the period 2007-2012, 74 waterworks obtained such permits, but of those, only eight (representing c. $2.5 \%$ of treated groundwater) were for carbon filters to treat for 2,6-dichlorobenzamide (BAM) or other organic micropollutants (Naturstyrelsen 2012). In the period 2012-2019, the number of permits granted for advanced treatment increased to 110 , of which 12 were for carbon filters (Miljøstyrelsen 2020a).
In addition to advanced treatments, waterworks could address non-compliance by closing polluted wells or well fields, diluting non-compliant water with groundwater from another well or importing unpolluted water from neighbouring waterworks.

All laboratory results of both drinking water and groundwater samples in Denmark are reported to the Danish National Well database (Jupiter), according to the national guidelines (Miljøstyrelsen 2020b). Based on these data, the Geological Survey of Denmark and Greenland (GEUS) has reported the status of raw groundwater in Denmark on an annual basis for the past 30 years (Thorling et al. 2019). Additionally, the Danish Environmental Protection Agency (EPA) conducted a mass screening in 2019, where 263 groundwater wells were tested for 415 pesticides (Mathiesen 2020). Based on these tests, the Danish EPA planned to revise the list of pesticides for mandatory compliance monitoring of drinking water and to intensify its control efforts against illegal imports of pesticides (Mathiesen 2020). Our study provides a national assessment of pesticides in Danish treated drinking water, supplied by public waterworks and on that basis an estimation of households exposed to pesticides from drinking water.

\section{Methods and materials}

The complete workflow used in this study is presented schematically in Fig. 1. A similar exposure-estimation methodology was used previously (Schullehner \& Hansen 2014; Voutchkova et al. 2015). Here, we outline all data-handling procedures to assure reproducibility and transparency, and to facilitate the potential future use of the drinking water dataset.

\subsection{Data sources}

The final dataset (Fig. 1) used for the status overview and to estimate pesticide exposure was prepared by combining data from four different sources.

\subsubsection{Drinking water samples analysed for pesticides}

All chemical analyses of drinking water reported to Jupiter were extracted on 5 May 2020 (Fig. 1, Step 1). This raw dataset was passed through a pre-processing procedure including various filtering and quality control steps summarised here and presented in full detail in Supplementary File S1. Compound selection was based on the latest version (20 May 2020) of the Jupiter list of pesticides, their degradation products and related substances ('50 - Pesticider, nedbrydningsprodukter og beslægtede stoffer' in Jupiter). Only samples of treated drinking water taken at the waterworks (i.e. the finished product), from the distribution network or the consumer's tap were kept in 


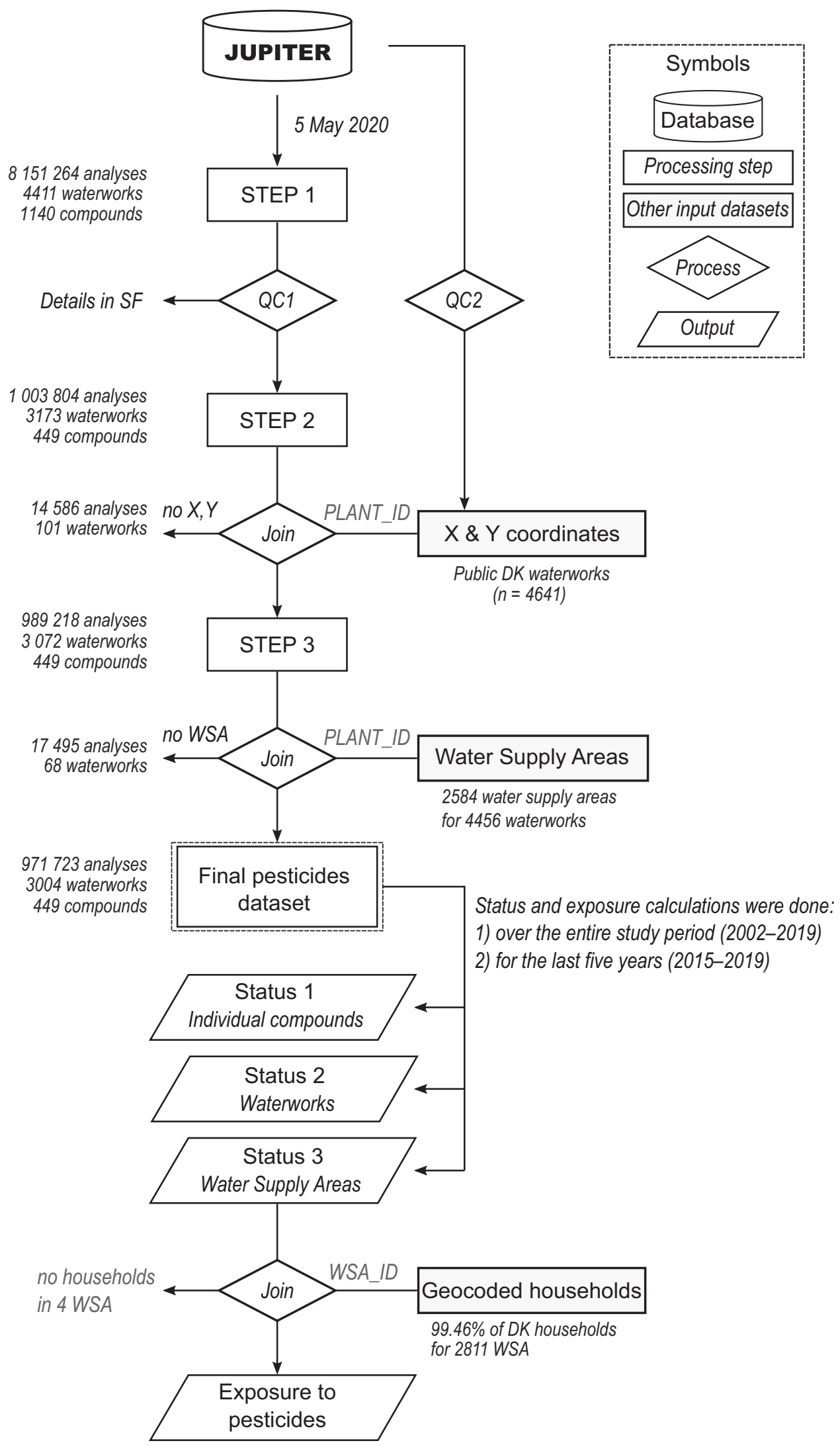

Fig. 1 Workflow including data-processing steps and overview of excluded chemical analyses and waterworks. DK: Denmark. WSA: Water supply areas. QC: Quality control and filtering procedures (see text for details). PLANT_ ID and WSA_ID: waterworks and WSA ID numbers, respectively, used when combining the datasets. SF: Supplementary Files.

the dataset (see Supplementary File S1, Section 1.1, Step 4 for details). We filtered out flagged or erroneous data and those data rejected by the data-owner. Analytical units were checked and converted when necessary to $\mu \mathrm{g} / \mathrm{l}$. All analyses below detection limit in instances where that detection limit was high $(>0.02$ $\mu \mathrm{g} / \mathrm{l})$ were excluded due to low precision of the laboratory method. After the pre-processing procedure 
(Supplementary File S1, Section 1.1), the resulting dataset contained all pesticide analyses of treated drinking water for the period 2002-2019 from public waterworks ( $n=3173$; Fig. 1, Step 2).

\subsubsection{Geographic coordinates of the waterworks}

The geographic coordinates of all waterworks were extracted from Jupiter and passed through a quality control. Missing $X$ and $Y$ coordinates were geocoded based on the registered address. Coordinate errors were identified and fixed when possible. Only coordinates for public waterworks ( $n=4641$ ) were kept, from which $5.5 \%$ ( $n=256)$ were geocoded based on address.

\subsubsection{Water supply areas of the waterworks}

The water supply areas (WSAs) for all public waterworks, covering the entire country, were provided by Schullehner and Hansen (2014). We assumed that WSAs were static in the study period (2002-2019), reflecting their state at the time the data were published (2014).

\subsubsection{Percent of households located within a WSA}

Geocoded locations of households were provided by the Centre for Integrated Register-Based Research at Aarhus University (CIRRAU), Denmark. This data source contains all residential addresses in Denmark registered in the Danish Civil Registration System ( $n=2086$ 797; Pedersen 2018). Just $0.54 \%$ of all households fell outside a polygon for the WSA.

\subsection{Data joining procedure}

Data from the four sources were combined using a stepwise procedure ('join' in Fig. 1). The pre-processed pesticide dataset from Step 2 was joined with the waterworks' coordinates. In this step, we excluded 101 waterworks with all their analyses. Most of these were waterworks located in Greenland ( $n=70)$, and four were identified as misclassified private waterworks. The remaining waterworks ( $n=27$ ) had no coordinates or a registered address and could not be geocoded. Of these, only four were actually waterworks, and the rest were locations at the supply network or at the consumers' tap. Then, the dataset (Fig. 1, Step 3) was joined with the WSA data, resulting in the exclusion of 68 waterworks which could not be assigned a WSA. We refer to this dataset as the final pesticide dataset.

\subsection{Final pesticide dataset}

The final pesticide dataset includes 39798 treated drinking-water samples (7 January 2002-30 Dec 2019) analysed for 449 pesticides (number of individual analyses $n=971$ 723), associated with public waterworks located in Denmark $(n=3004)$ with known X and $Y$ coordinates and WSA. Figure 2 shows the spatial distribution of these waterworks, the number of waterworks within the WSA and the percent of households in each WSA.

The final dataset was used further to produce the status overviews of individual pesticides, waterworks and WSAs (Status 1, 2 and 3 in Fig. 1). The population exposure to pesticides from drinking water was obtained by combining Status 3 results (Fig. 1) with the percentage of households with each WSA (Fig. 2). The methodology for these status overviews and the exposure assessments are presented in Section 3.4. First, we present the methodology for how we handled values below the detection/quantification limit and discuss the data structure.

\subsubsection{Limit of detection and quantification}

The laboratories performing the chemical analyses report the limit of detection (LOD) in the Jupiter database. All measurements below the LOD are recorded with the attribute ' $<$ ' and a value equal to the LOD (e.g. $<0.01 \mu \mathrm{g} / \mathrm{l}$ ). Most of the pesticide analyses in the final dataset were below the specified LOD $(98.8 \%, n=$ 960 437). LOD varied from $0.4 \mathrm{ng} / \mathrm{l}$ to $0.02 \mu \mathrm{g} / \mathrm{l}$. Analyses with higher LODs were excluded in the pre-processing. The most frequent LOD was $0.01 \mu \mathrm{g} / \mathrm{l}(99.2 \%, n=$ 953 120), followed by $0.02 \mu \mathrm{g} / \mathrm{l}(0.6 \%, n=5522$; see Supplementary File S1). The variation in LODs reflects the variety of methods used by different laboratories, with liquid chromatography-mass spectrometry (LC/MS/MS) being the most frequently used method (see Supplementary File S1). The variation with time is also due to possible instrumentation improvements, reducing the LOD during the study period.

In the status assessments and the exposure estimation, we use the limit of quantification (LOQ) instead of the LOD to avoid the effect of false positive detections and to reduce the influence of the high uncertainty in concentrations measured near the LOD. Evidence of the variability around the LOD is presented in Section 3.3.2. The LOQ was calculated according to the Ministerial Order on quality requirements for environmental measurements (BEK nr 1071, 28 October 2019) with the formula LOQ $=3 \times L O D$, where LOD here is the most frequent $\operatorname{LOD}(0.01 \mu \mathrm{g} / \mathrm{l})$. Thus, $\mathrm{LOQ}=0.03 \mu \mathrm{g} / \mathrm{l}$ (equal to $30 \%$ of the DWQS). For all analyses with concentrations less than LOQ, we adopt the definition that 'pesticides were not determined with an acceptable level of accuracy and precision' (Commission of the European Communities 2009). For brevity, we use 'non-detect' or 'never detected', where this definition applies to a period of time or pesticide, respectively. 
A
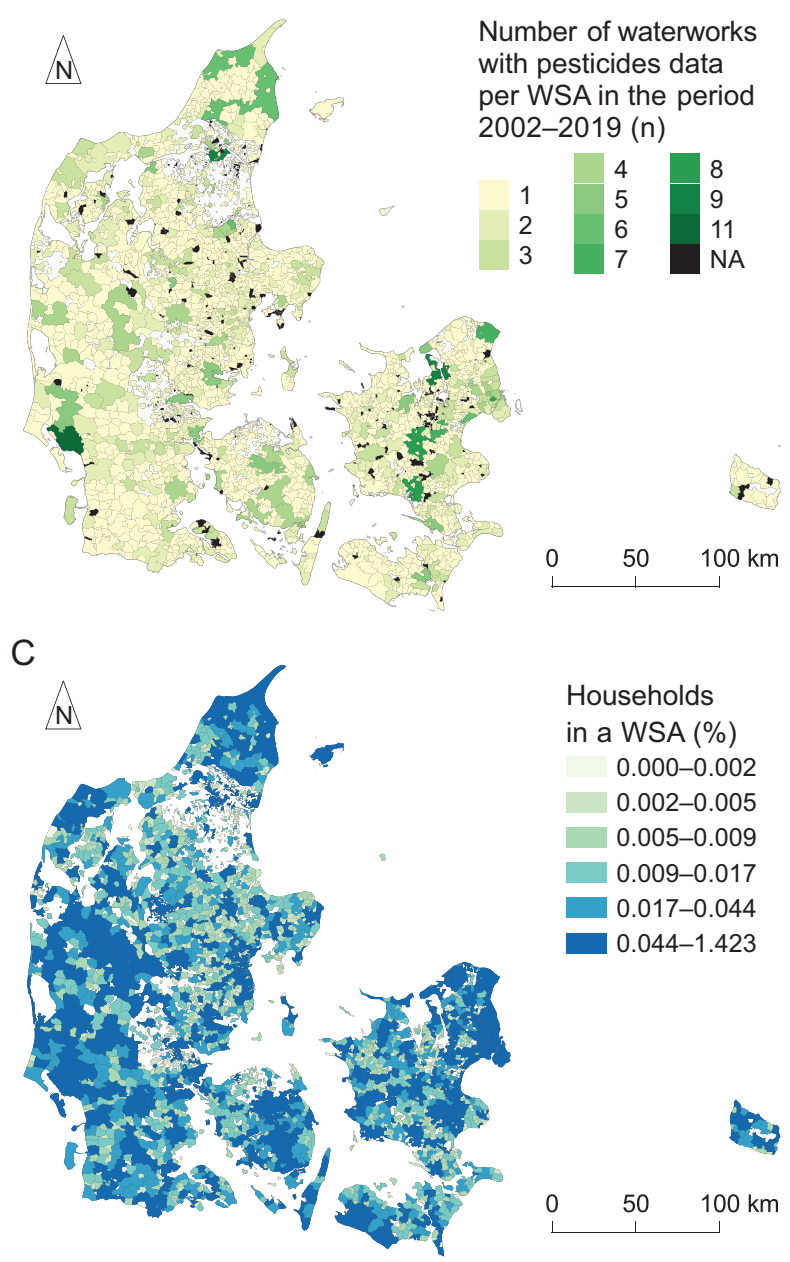

B

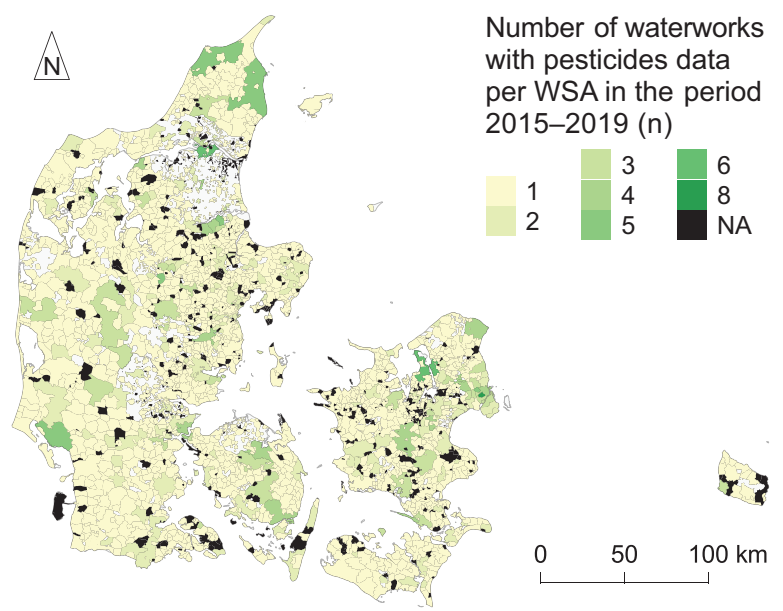

D

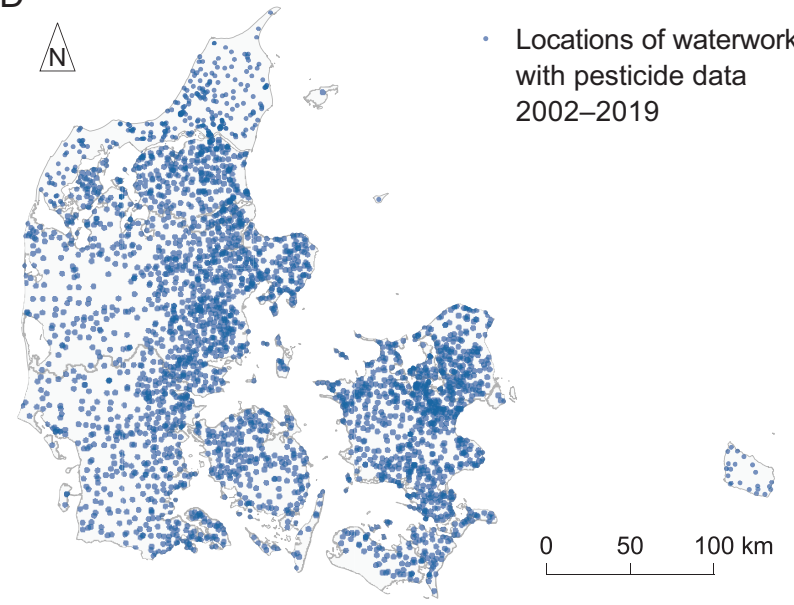

Fig. 2 Number of public waterworks with pesticide data for each water supply area (WSA) for A: the entire study period (2002-2019) and B: the last five years (2015-2019). C: Percentage of Danish households ( $n=2086$ 797) located in each of the WSA, equal count in each interval. D: Location of all public waterworks with at least one pesticide analysis in the period 2002-2019 included in the final dataset. Note: the symbols in D have transparency to visualise overlapping locations. NA: no data.

\subsubsection{Structural heterogeneity}

The final dataset structure is characterised by many types of heterogeneity. Here we illustrate those caused by (1) the dynamic nature of the analytical program, (2) the varying sampling frequency and consequently the varying length of the sampling gaps and (3) the variability of the analytical results around the LOD.

Inspecting the timeseries of individual pesticides at various waterworks shows that it is not uncommon to have concentrations varying around the LOD. This includes frequent changes between detects (concentrations $\geq L O D$ ) and non-detects (concentrations $<L O D$ ), sometimes within the same sampling event (see Supplementary File S1 for examples). We quantified this instability by counting the number of changes from $<$ LOD to $\geq$ LOD for each waterworks and each pesticide. Figure 3 shows the proportion of waterworks where such changes occurred for individual pesticides. The least stable results around the LOD are for BAM - about $15 \%(n=469)$ of all waterworks with BAM analyses in the study period ( $n=2997$ ) had multiple changes. Bentazon ( $n=89)$, dichlorprop ( $n=63)$, atrazine-desisopropyl ( $n=$ 56) and desphenyl chloridazon (DPC; $n=53$ ) are in the top five based on the absolute number of waterworks with multiple changes around the LOD.

The dynamic nature of the analytical programme for pesticides is reflected in the data availability for each pesticide in the final dataset. The period covered for individual pesticides varies from 1 to 18 years (20022019); $64.8 \%$ of all 449 pesticides were only analysed in 1 year, while $14.7 \%$ were analysed throughout the entire study period (Fig. 4A). Many pesticides (71\%) were analysed for the first time in 2018 or 2019 (Fig. 4B). The latest sampling date for almost all pesticides was in $2019(n=$ $432,96.2 \%)$.

The third heterogeneity aspect relates to the sampling frequency. The number of sampling events at the 


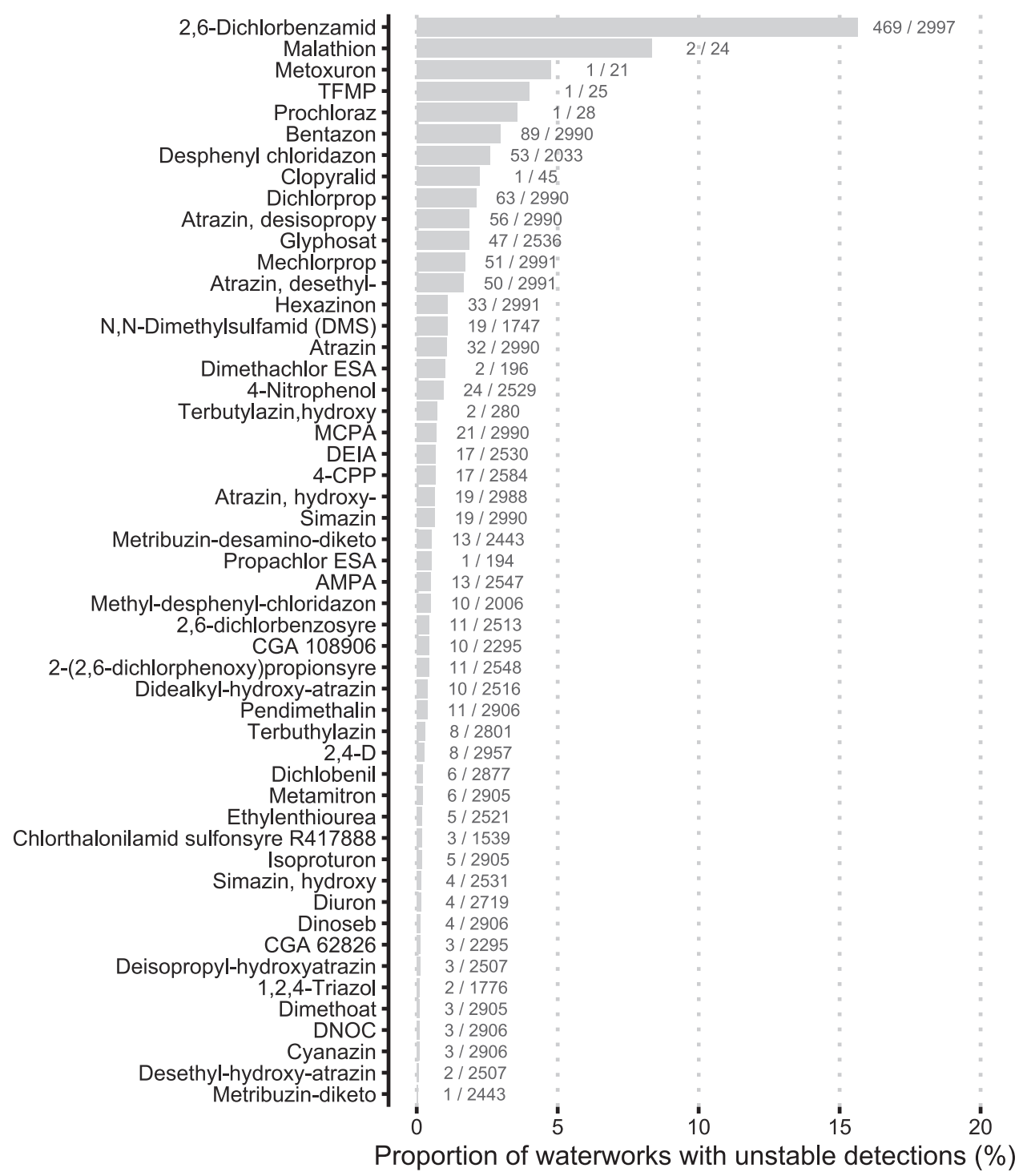

Fig. 3 Proportion of waterworks with 'unstable' detections of pesticides during the study period (2002-2019). 'Unstable' is defined here as having more than one fluctuation around the LOD (i.e. multiple changes from $\angle \mathrm{LOD}$ to $\geq$ LOD or vice versa). Data labels in the format $\mathbf{n} / \mathbf{n}$ indicate number of waterworks with unstable detections versus all waterworks with pesticide data. Pesticides labels are used as provided in Jupiter database.

3004 waterworks varies from once to $>200$ times within the study period (2002-2019) with the most common being nine times (7.9\% of the waterworks; Fig. 5A). Of all waterworks, $4.6 \%$ had only one sampling event in that period. In the past five years, there were 2405 waterworks with data, of which $7.6 \%$ had only one sampling event. The most common sampling frequency was 3 times (at 19.9\% of the waterworks; Fig. 5B). Because of the variation in sampling frequency, the data gaps also vary. Figure $5 \mathrm{C}$ and $\mathrm{D}$ shows the mean sampling gap (the number of days between sampling events) for 20022019 and 2015-2019, respectively.

\subsection{Status assessment and exposure estimation}

The status assessment is presented in four qualitative groups based on the determined pesticide concentrations as follows: ( 1 ) never detected ( $<$ LOQ, where LOQ = $0.03 \mu \mathrm{g} / \mathrm{l})$, (2) detected but always $\leq 0.1 \mu \mathrm{g} / \mathrm{l}$, (3) exceeded
$0.1 \mu \mathrm{g} / \mathrm{l}$ (the DWQS for individual pesticides) and (4) not analysed (no data). A pesticide had to be detected or exceed the DWQS at least once within the period of interest (Status 2) and for at least one waterworks in the WSA (Status 3). Where a WSA contained multiple waterworks (Fig. 2), the entire area was classified as exceeding the DWQS if at least one exceeded the DWQS.

The exposure to pesticides from drinking water was then estimated for the following four exposure classes: (1) never exposed to pesticides from drinking water, (2) potentially exposed to low concentration of pesticides (0.03-0.1 $\mu \mathrm{g} / \mathrm{l})$, (3) potentially exposed to concentrations exceeding the DWQS (>0.1 $\mu \mathrm{g} / \mathrm{l})$ and (4) unknown exposure due to no data. These general classes of exposure were selected because of the structural heterogeneity of the final dataset (Section 3.3.2). Our methodology is in line with the deterministic approaches for estimating exposure, which usually include worst-case assumptions and result in a conservative estimate of exposure (Ferrier et al. 2002). 
A

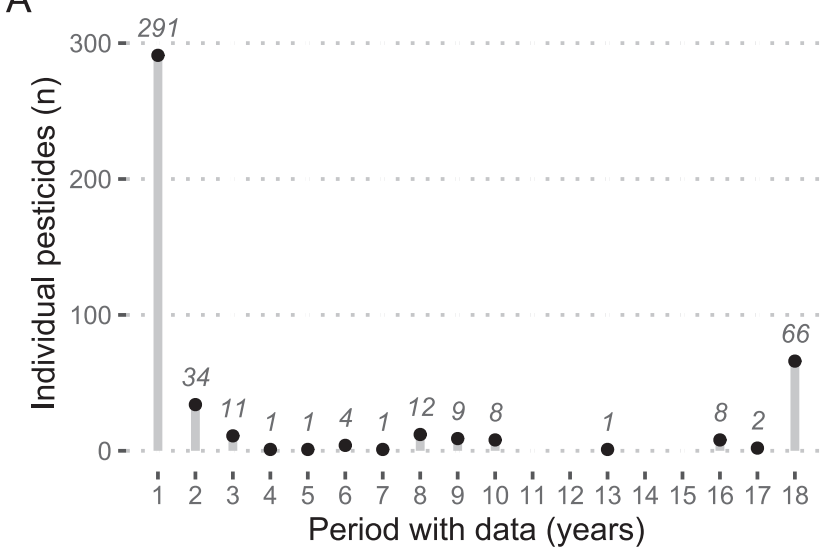

B

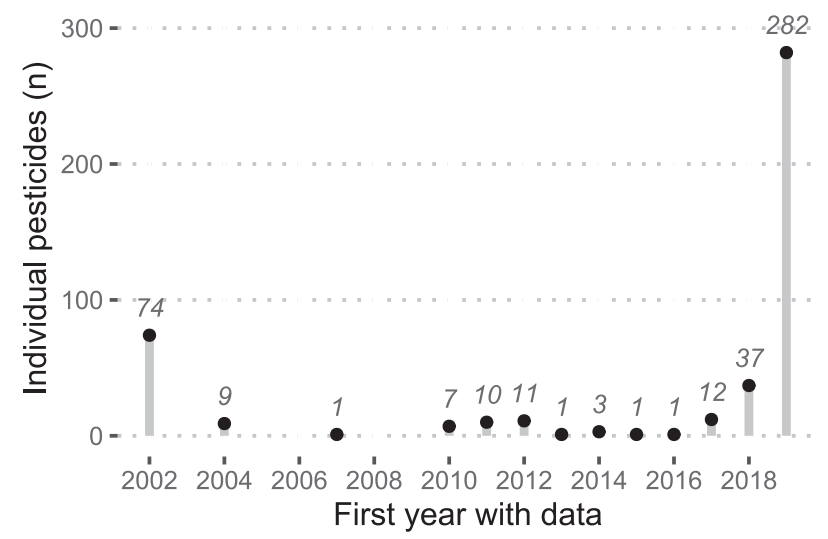

Fig. 4 Data availability. A: Period (in years) where data are available for individual pesticides, calculated as the difference between first and last sampling date for each of the 449 compounds. B: The year when individual pesticides were first measured. Data labels show the number of individual pesticides.

A

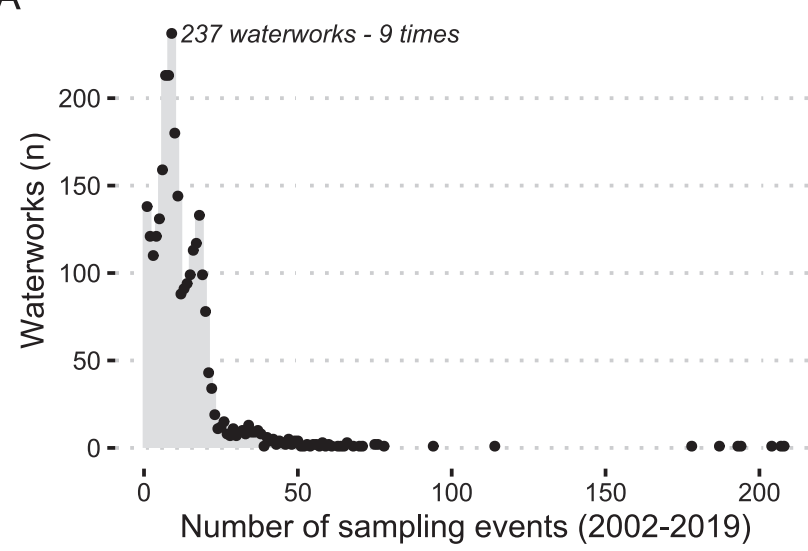

C

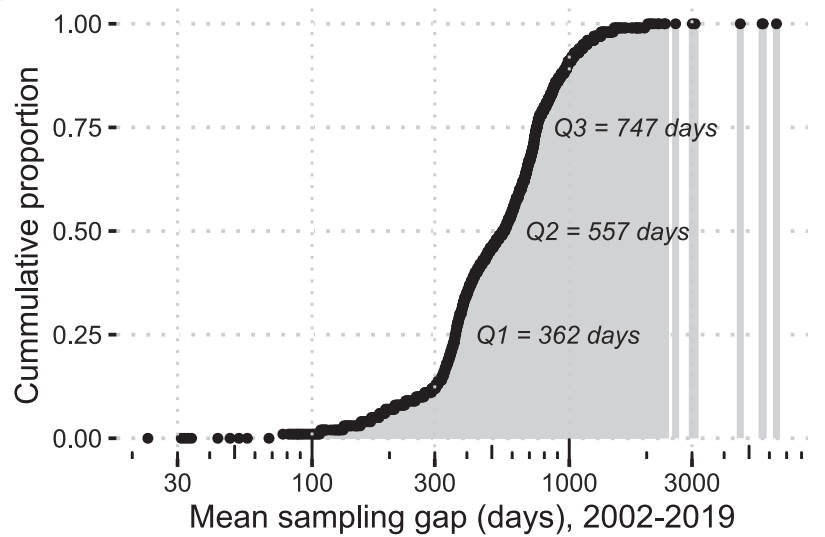

B

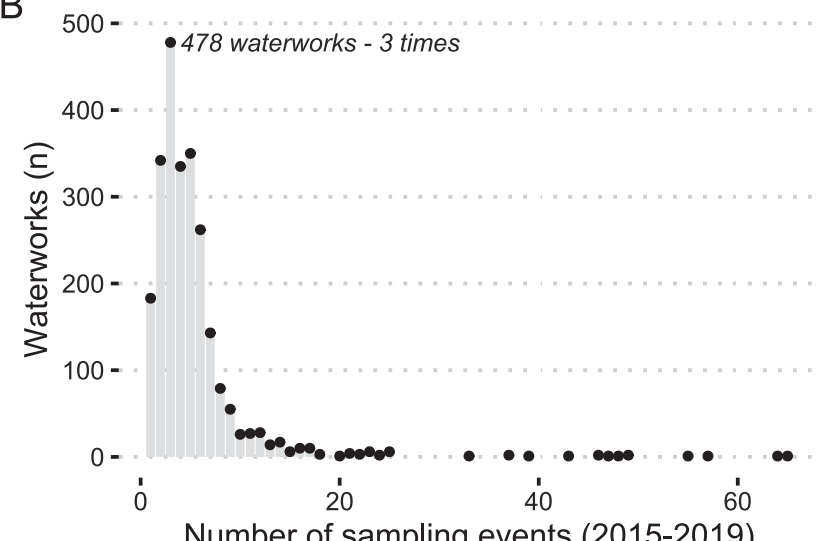

Number of sampling events (2015-2019)

D

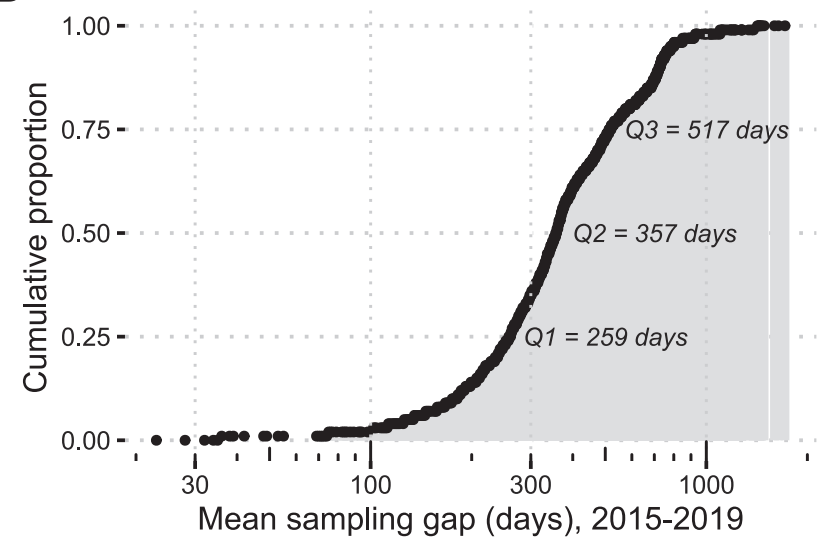

Fig. 5 Frequency of sampling events by sampling date in A: 2002-2019 and B: 2015-2019. The cumulative proportion of the mean sampling gap per waterwork (period between two sampling events) in C: 2002-2019 and D: 2015-2019. C and D include only waterworks with more than one sampling event ( $n=2866$ for $C ; n=2222$ for $D)$.

Status 1 for individual pesticides (Fig. 1) encompasses the entire study period (2002-2019), while the status of waterworks and WSAs (Status 2 and 3) and the exposure estimates were prepared for both 2002-2019 and 20152019. By using two periods, we can account for potential changes due to the measures taken by waterworks to comply with the DWQS limits. Only waterworks with a minimum of one pesticide analysis in the respective period are included in these calculations. The methodological details for status assessments for the sum of 
pesticides (i.e. 'Pesticides - Total' in the DWD) are provided in Supplementary File S1, Section 2.4.

\subsection{Software}

All data processing and analyses were done in $\mathrm{R}$ v.3.6.0 (R Core Team 2019) and RStudio Desktop 1.2.1335 (RStudio Team 2018) with additional R packages (Wickham 2016; Dowle \& Srinivasan 2019; R Core Team 2019; Wickham \& Henry 2019; Wickham et al. 2019). QGIS Desktop v.3.6.1 (QGIS Development Team 2019) and Inkscape v.0.92.4 (Inkscape Project 2019) were used to produce the maps and flowchart, respectively.

\section{Results}

4.1 Status overview 1 - individual compounds A total of $99.5 \%$ of the individual analyses in the final dataset were <LOQ $(n=966798)$ and 0.5\% $(n=4925)$ contained a detected and quantified pesticide $(\geq 0.03$ $\mu \mathrm{g} / \mathrm{l})$. Of these, $16 \%(n=793)$ exceeded DWQS.

In the period $2002-2019,10.2 \%$ of the 449 pesticides ( $n=46)$ were detected in at least one sample. Of those, BAM was analysed at most of the waterworks ( $n=2997)$. BAM is a degradation product of the banned herbicides dichlobenil and chlorthiamid, used for weed control in urban areas and in berry production in the period 1969-1996 (Thorling et al. 2019). BAM has been analysed throughout the entire study period and has the largest total number of analyses ( $n=36777$ ), of which $6.8 \%$ contained a detected pesticide $(n=2514)$, but only $0.9 \%(n=330)$ exceeded the DWQS $(0.1 \mu \mathrm{g} / \mathrm{l})$. The maximum detected concentration of BAM in the study period was $1.9 \mu \mathrm{g} / \mathrm{l}$.

The absolute maximum detected concentration was $4 \mu \mathrm{g} / \mathrm{l}$ for DPC. DPC is a degradation product from the banned herbicide chloridazon, sold in Denmark between 1964 and 1996 (Thorling etal. 2019). DPC was analysed at 2033 public waterworks in the period 2016-2019 (except for a single analysis in 2010). From all reported DPC analyses $(n=5140), 14.4 \%$ contained a detected pesticide $(n=739)$, but only $4.4 \%(n=227)$ exceeded the DWQS.

Next to BAM and DPC, DMS (N,N-dimethylsulfamide) is also in the top three of pesticides that exceeded DWQS (in terms of absolute number of analyses). DMS is a degradation product from the fungicides tolylfluanid and dichlofluanid, which have been applied as both pesticides and biocides (Thorling et al. 2019). DMS has been analysed at 1747 waterworks since March 2018. About $18 \%$ of the 3333 DMS analyses contain a detected pesticide $(n=620)$, and 83 (2.5\%) exceeded the DWQS.

Aldrin, dieldrin, heptachlor and heptachlor epoxide (DWQS $=0.03 \mu \mathrm{g} / \mathrm{l})$ were reported since 2018 at 1631 waterworks (aldrin, dieldrin and heptachlor) and 1600 waterworks (heptachlor epoxide). The complete Status 1 overview including all 449 individual substances is provided in Supplementary File S2.

\subsection{Status at waterworks and WSAs}

(Status 2 and 3 ) and pesticide exposure

Pesticides were detected at least once in drinking water $(\geq 0.03 \mu \mathrm{g} / \mathrm{l})$ at $29 \%$ of the waterworks in the study period (2002-2019) and at 24\% of the waterworks with measurements in the last five years (2015-2019; Fig. 6). About 9\% of all waterworks exceeded the DWQS $(>0.1 \mu \mathrm{g} / \mathrm{l})$ in the study period and $7 \%$ in the past five years. The rest of the waterworks (71-76\%) had never detected and quantified a pesticide $(\mathrm{LOQ}=0.03 \mu \mathrm{g} / \mathrm{l})$ based on the final dataset. Figure 7A and B provide a spatial visualisation of waterworks status.

The status of WSAs (Status 3) resembles that for waterworks with minor differences in the percentages (Table SM-4 in Supplementary File S1). Twelve percent of the WSAs had at least one waterworks that exceeded the DWQS in 2002-2019, dropping to less than $8 \%$ when only the past five years were considered. The difference between the two periods can also be observed in Fig. 7C and D. Status 3 was used to estimate the population exposure, based on the percent of households located in each WSA.

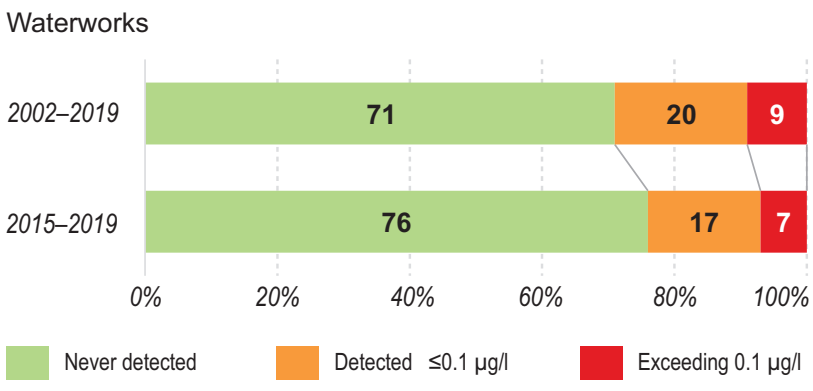

Households

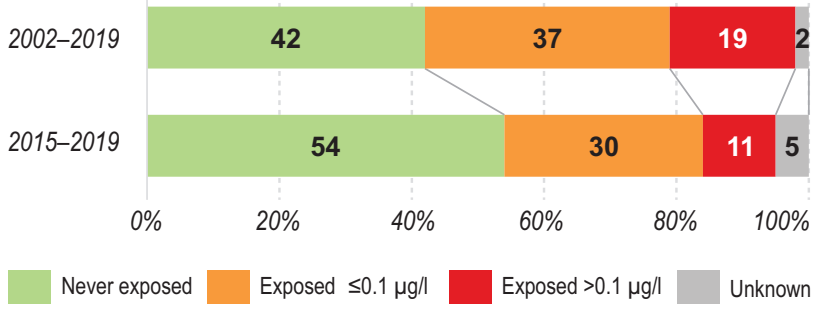

Fig. 6 Pesticide status at waterworks and estimated exposure at the household level. Note: The classes 'never detected' and 'never exposed' refer to pesticide concentrations below the limit of quantification (LOQ $=0.03 \mu \mathrm{g} / \mathrm{l})$. For absolute numbers, see Table SM-4 in Supplementary File S1. 
A

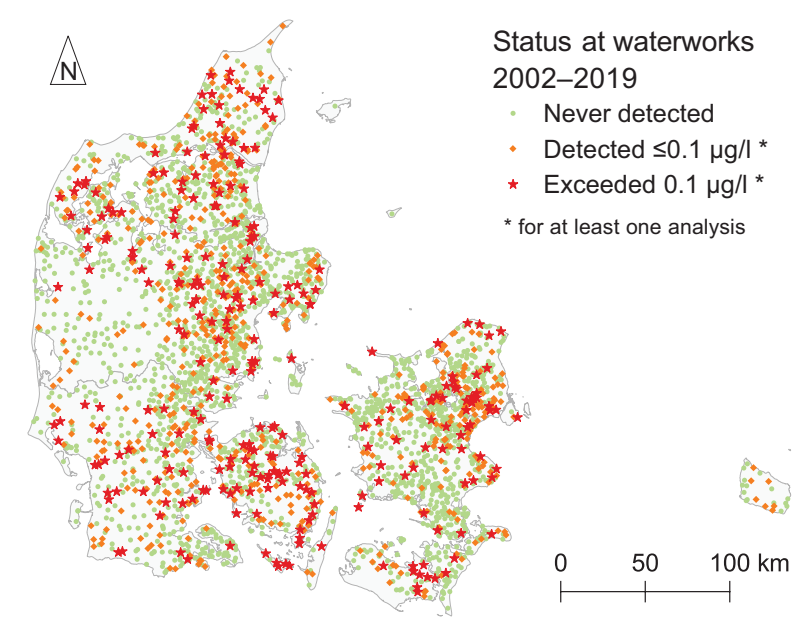

$\mathrm{C}$

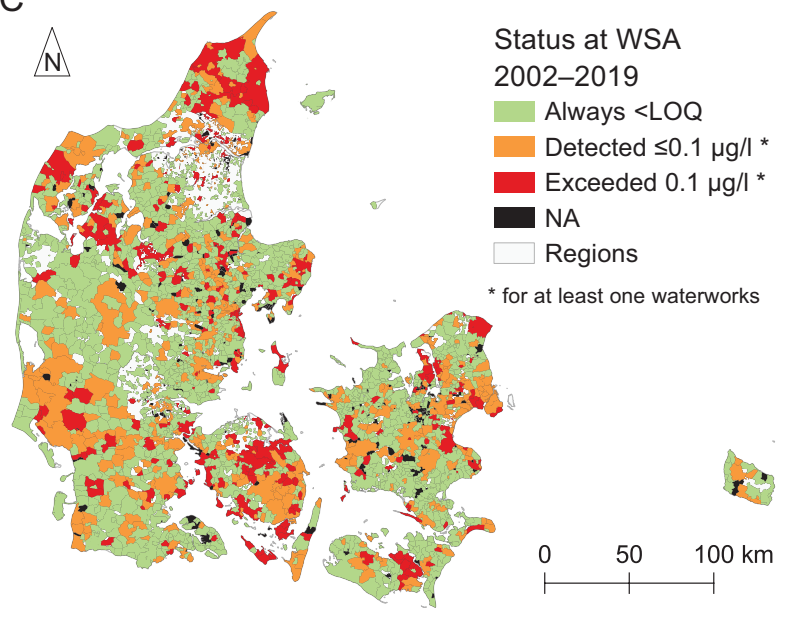

B

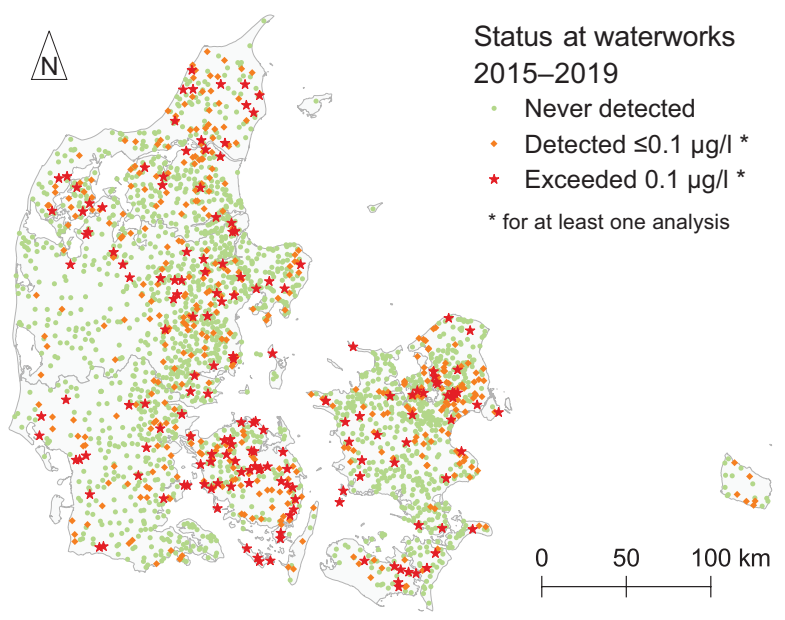

D

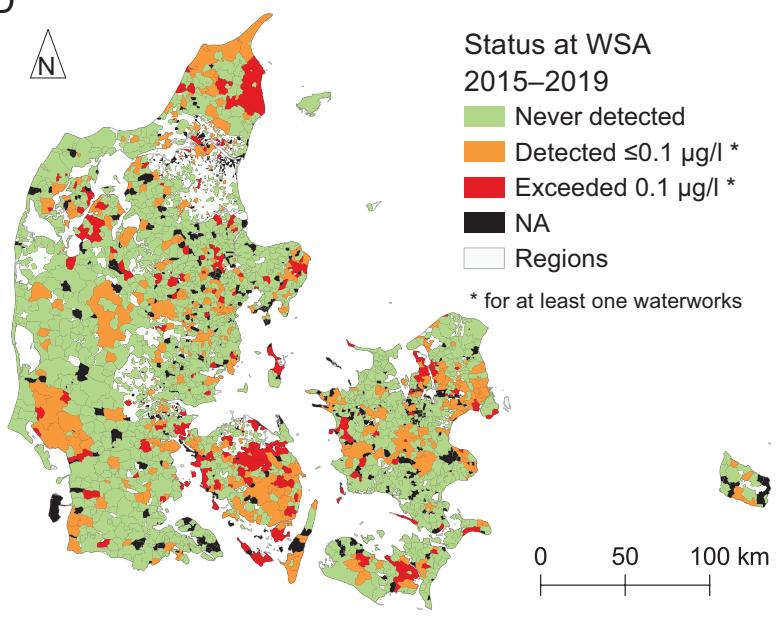

Fig. 7. Pesticide status at waterworks and water supply area (WSA). 'Never detected' refers to all analyses or waterworks where pesticides are measured below the quantification limit $(\mathrm{QOL}=0.03 \mu \mathrm{g} / \mathrm{l})$. NA: no data.

Based on the final dataset, about half of all Danish households (54\%) were never exposed to the pesticides analysed between 2015 and 2019 (Fig. 6). This was lower (42\%) for the period 2002-2019. However, fewer households were exposed to low pesticide concentrations $(0.03-0.1 \mu \mathrm{g} / \mathrm{l})$ in the past five years $(30 \%)$ compared to the entire study period. Similarly, the households potentially exposed to pesticides exceeding $0.1 \mu \mathrm{g} / \mathrm{l}$ were $19 \%$ for 2002-2019 and 11\% for 2015-2019. For status with respect to 'Pesticides-Total' $(0.5 \mu \mathrm{g} / \mathrm{l})$, see Supplementary File $\mathrm{S} 1$.

We could not estimate the exposure for $2 \%$ (20022019) and 5\% (2015-2019) of Danish households due to lack of data - 599 waterworks had no data after 2015, hence the higher percent for 2015-2019. Some of these waterworks may have closed, but it is also possible that there is a delay in reporting to the Danish database or that the analyses were excluded in the quality assurance procedures or the other data-preparation steps.

\section{Discussion}

\subsection{Possible trends}

During the period 2002-2019, Danish drinking water has been tested for 449 individual substances defined here as pesticides, resulting in more than 970000 individual analyses. Of which, less than $5000(0.5 \%)$ contained a quantified pesticide. BAM has the most spatially and temporally complete data coverage.

A tenth of all Danish households connected to public water supplies were potentially exposed to pesticides from drinking water at concentrations $>0.1$ $\mu \mathrm{g} / \mathrm{l}$ and about $30 \%$ to concentrations in the range 0.03-0.10 $\mu \mathrm{g} / \mathrm{l}$ during the past five years (2015-2019). Pesticides exposure from drinking water (and the waterworks status) is lower (better) in the period 2015-2019 when compared to the entire 18-year study period. The reduction in those exposed in the past five years could be due to improved groundwater quality. Also, some of the waterworks where concentrations exceeded the DWQS may have (1) closed before 2015, 
(2) closed or changed wells and well-fields, changed their pumping strategies or started importing water from other waterworks or (3) implemented advanced treatment processes for pesticide removal. Thus, this might indicate that water supply companies in Denmark are working towards resolving compliance issues. However, we cannot directly compare two different periods (before/after) or do trend analysis due to the issue surrounding data heterogeneity (Fig. 3). Notably, DPC and DMS, the two compounds most discussed in Denmark today, were only analysed during the past five years.

\subsection{Comparison with untreated groundwater}

The pesticide content of untreated groundwater and treated drinking water was compared since all drinking water in Denmark originates from groundwater (Table 1). The status of the Danish groundwater is assessed and reported annually as part of the national groundwater-monitoring program (e.g. Thorling et al. 2019). However, such direct comparison between the pesticide status of treated drinking water and the raw, untreated groundwater at a national scale could be misleading. Often, raw groundwater is abstracted from multiple wells and well fields and mixed before or after the treatment. It is also possible that some pesticides are removed during treatment. In the most general terms, our results for the 2015-2019 period fit well with the findings for untreated groundwater. The percent of monitoring points with at least one detected pesticide is lower in drinking water (24\% for 2015-2019) than in groundwater (29\% for 2014-2018). This could be partly due to the different analytical programme and because we used a more conservative data-quality assurance. For example, we look at the detected and quantified pesticides based on LOQ $(0.03 \mu \mathrm{g} / \mathrm{l})$, while Thorling et al. (2019) used the $\operatorname{LOD}(0.01 \mu \mathrm{g} / \mathrm{l})$.

\subsection{Drinking water quality standard and health implications}

The DWQS for pesticides in the EU is based on the 'precautionary principle' (Bourguignon 2016). The DWQS for individual pesticides $(0.1 \mu \mathrm{g} / \mathrm{l})$ was a surrogate for zero when it was first introduced in 1980 (Dolan et al. 2013). It remained unchanged in the 1998 revision and was regarded by Dolan et al. (2013) to be still consistent with the precautionary principle. No changes to the DWQS for pesticides are planned in the revised Directive (European Commission 2018). The DWQS in the DWD was found to be one of the most conservative worldwide for 16 out of 25 of the most commonly regulated pesticides (Li \& Jennings 2018). Lower standards existed elsewhere for the following pesticides: lindane, chlordane, heptachlor, endrin, dibromochloropropane (DBCP), heptachlor epoxide, dichlorodiphenyltrichloroethane (DDT), aldrin and dieldrin (Li \& Jennings 2018).

The World Health Organization (WHO) drinking water guidelines, on the other hand, aim to protect against health effects resulting from a lifetime exposure (World Health Organization 2011, 2017). WHO guidelines (Table 2) are established only for pesticides of significant international concern when there is credible evidence for occurrence in drinking water and actual or potential toxicity (World Health Organization 2017). We detected and quantified about one-third of the pesticides for which WHO guideline values are established, although the maximum concentrations were lower than the WHO guidelines (Table 2). The WHO notes that as a general principle, concentrations of pesticides in drinking water should be kept as low as possible and increasing trends up to the guideline values should be prevented (World Health Organization 2017).

\subsection{Limitations}

\subsubsection{Drinking water pesticide data}

The Jupiter database is a comprehensive resource for both drinking and groundwater quality data since all laboratory samples taken from wells and waterworks

Table 1 Results from the pesticide status of untreated groundwater (Thorling et al. 2019)

\begin{tabular}{|c|c|c|c|c|c|}
\hline Sampling points & Water type & Sampling period & $\begin{array}{l}\text { Total monitoring } \\
\text { points }(n)\end{array}$ & $\begin{array}{c}\text { Detected }^{1} \\
(\%)\end{array}$ & $\begin{array}{c}\text { Exceeded } \\
(\%)\end{array}$ \\
\hline Monitoring wells ${ }^{2}$ & Groundwater & $2016-2018$ & 1084 & 42 & 18 \\
\hline Waterworks wells ${ }^{3}$ & Groundwater & $2014-2018^{4}$ & 6342 & 29 & 7 \\
\hline Waterworks ${ }^{5}$ & Drinking water & 2015-2019 & 2405 & 24 & 7 \\
\hline
\end{tabular}

The drinking water results from this study are presented for reference.

${ }^{1}$ For groundwater samples, 'detected' refers to concentrations $\geq 0.01 \mu \mathrm{g} / \mathrm{l}$. In drinking water, it refers to 'detected and quantified' (i.e. $\geq 0.03$ $\mu \mathrm{g} / \mathrm{l}) .{ }^{2} \mathrm{All}$ sampled intakes belonging to the monitoring wells from the Danish nation-wide monitoring programme (not for drinking water production; Thorling et al. 2019). ${ }^{3}$ All sampled intakes belonging to waterworks wells used for drinking water production from the analysis package 'Boringskontrol' (Thorling et al. 2019). ${ }^{4} \mathrm{All}$ waterworks wells in Denmark should have been tested for pesticides at least once in this period. The analytical programme expanded in 2018 , so these percentages will most likely change once all wells are tested for the complete list of pesticides. ${ }^{5}$ From this study. 
Table 2 Drinking water guideline values for pesticides (World Health Organization 2017) and occurrence in Danish drinking water based on our final pesticide dataset

\begin{tabular}{|c|c|c|c|c|c|c|c|}
\hline Pesticide & WHO-GV $(\mu \mathrm{g} / \mathrm{l})$ & $\operatorname{Max}(\mu g / l)$ & $\geq \operatorname{LOQ}(n)$ & WW $(n)$ & Total analyses $(n)$ & Since (year) & Found \\
\hline Aldrin and dieldrin & 0.03 & - & - & 1631 & 2698 & 2018 & No \\
\hline Chlordane & 0.2 & - & - & 11 & 11 & 2019 & No \\
\hline 1,2-Dibromoethane & 0.4 & - & - & - & - & - & - \\
\hline Cyanazine & 0.6 & - & - & 2906 & 20015 & 2002 & No \\
\hline Endrin & 0.6 & - & - & 11 & 11 & 2019 & No \\
\hline 1,2-Dibromo-3-chloropropane & 1 & - & - & - & - & - & - \\
\hline MCPA & 2 & 1.23 & 12 & 2900 & 35153 & 2002 & Yes \\
\hline Simazine $^{1}$ & 2 & 0.051 & 16 & 2990 & 35088 & 2002 & Yes \\
\hline Lindane & 2 & - & - & 23 & 35 & 2019 & No \\
\hline Molinate & 6 & - & - & - & - & - & - \\
\hline Dimethoate & 6 & - & - & 2905 & 20102 & 2002 & No \\
\hline Terbuthylazine & 7 & 0.031 & 2 & 2801 & 19657 & 2002 & Yes \\
\hline Carbofuran & 7 & - & - & 33 & 387 & 2002 & No \\
\hline Isoproturon & 9 & 0.12 & 4 & 2905 & 20402 & 2002 & Yes \\
\hline Fenoprop & 9 & - & - & - & - & - & - \\
\hline $2,4,5-\mathrm{T}$ & 9 & - & - & 131 & 623 & 2002 & No \\
\hline Mecoprop & 10 & 0.74 & 52 & 2991 & 35185 & 2002 & Yes \\
\hline Aldicarb & 10 & - & - & 11 & 11 & 2019 & No \\
\hline Metolachlor & 10 & - & - & 38 & 111 & 2018 & No \\
\hline Pendimethalin & 20 & 0.057 & 3 & 2906 & 20205 & 2002 & Yes \\
\hline 1,3-Dichloropropene & 20 & - & - & - & - & - & - \\
\hline Alachlor ${ }^{2}$ & 20 & - & - & 38 & 126 & 2018 & No \\
\hline Methoxychlor & 20 & - & - & 11 & 11 & 2019 & No \\
\hline Trifluralin & 20 & - & - & 129 & 844 & 2002 & No \\
\hline $2,4-D$ & 30 & 0.08 & 2 & 2957 & 29020 & 2002 & Yes \\
\hline Chlorotoluron & 30 & - & - & 11 & 11 & 2019 & No \\
\hline Chlorpyrifos & 30 & - & - & 22 & 23 & 2019 & No \\
\hline 1,2-Dichloropropane & 40 & - & - & - & - & - & - \\
\hline $2,4-\mathrm{DB}$ & 90 & - & - & 11 & 11 & 2019 & No \\
\hline Atrazine $^{3}$ & 100 & 0.26 & 43 & 2990 & 35132 & 2002 & Yes \\
\hline Dichlorprop & 100 & 0.87 & 82 & 2990 & 35120 & 2002 & Yes \\
\hline Hydroxyatrazine & 200 & 0.12 & 5 & 2988 & 35050 & 2002 & Yes \\
\hline
\end{tabular}

WHO-GV: World Health Organization (WHO) guideline value for drinking water. Max: Maximum detected and quantified concentration. $\geq$ LOQ: Analyses above the limit of quantification $(0.03 \mathrm{ug} / \mathrm{l})$. WW: Number of waterworks where the specific pesticide was analysed at least once in the study period. Since: The first year of analyses (in the dataset). Found: Yes or no, indicating if the pesticide was found in Danish drinking water. ${ }^{1} \mathrm{~A}$ simazine metabolite had higher maximum concentration (detected and quantified in 29 analyses max $=0.12 \mu$ g/l). ${ }^{2} \mathrm{Alachlor}$ 's metabolite was detected and quantified 3 times (range $0.05-0.08 \mu \mathrm{g} /$ ). ${ }^{3}$ The guideline value also covers the chloro-s-triazine metabolites. Desethyl atrazine, desisopropyl atrazine, hydroxyatrazine and desethyl-desisopropyl atrazine (DEIA) were also detected and quantified here.

in Denmark must be entered into it. However, reporting is dynamic and may be incomplete or delayed. It is also possible for the data owners to revise historical data. We based our assessment on data extracted in May 2020, but if this work is reproduced with data extracted at a later date, there may be some differences in the results. When using Jupiter water-quality data for research purposes, it is imperative to implement stringent data-cleaning protocols. We set various quality control criteria (see Supplementary File S1), resulting in the exclusion of pesticide analyses that did not meet those criteria. Consequently, if raw Jupiter data are used directly, or if different quality criteria are set, the results may differ from this assessment and our exposure estimates.

The pesticides dataset is inherently heterogeneous and complex to work with due to the dynamic analytical programme, variable sampling frequency, high number of censored values and the variability around the LOD.

The dynamic analytical programme is a result of the frequent updates in national legislation in Denmark regarding the list of mandatory pesticides for compliance monitoring. The final dataset structure reflects these changes in national legislation, but also the highly decentralised and asynchronous local response to newly discovered threats in groundwater catchments. Currently, the list for mandatory compliance testing contains 46 pesticides (BEK nr 1070, 28 October 2019), but new pesticides were included to the list in 2012 ( $n=18), 2014$ ( $n=3) ; 2017$ (DPC and methyl desphenylchloridazon; MDPC), 2018 (1,2,4-triazol and DMS) and 2019 (chlorothalonil sulfonic acid) (Thorling et al. 2019). Further, eight pesticides were removed in 2012, and 
2,4-D was removed in 2015 (Thorling et al. 2019). This changes the temporal or spatial data-coverage of individual pesticides (Fig. 3), which should be considered in future uses of our final dataset.

The different sampling frequency and consequently the varying length of data-gaps (Fig. 4) can be explained by the legal requirements for minimum frequency of compliance testing, linked to the produced volumes of treated drinking water. For public waterworks, the mandatory sampling frequency varies from once every three years to once a month. However, water supply companies may choose to sample more often. As a result, the timeseries for individual pesticides and waterworks are highly irregular. Combined with the large number of non-detects and the instability around the LOD (Fig. 5), interpolation to fill in missing concentration values in the pesticides timeseries should be avoided. We have introduced the qualitative group 'not-analysed' (or 'unknown due to no data') to retain this missing information. Any statistical treatment of datasets with so many censored values poses a major challenge (Helsel 2005; Antweiler \& Taylor 2008; Antweiler 2015; Stow et al. 2018). The issue has been discussed specifically in the context of performing descriptive statistics and trend analysis of pesticides in Danish groundwater (Hansen et al. 2015, 2016; Johnsen et al. 2016). Due to the high percent of censored data in this dataset, simple substitution methods should be avoided. Appropriate methods for the treatment of censored values are outlined in the references cited above. Our assessment only required counting of analyses within the selected qualitative classes, and thus, substitution of concentrations <LOD or LOQ was unnecessary. For the 'Pesticides-Total' (Supplementary File S1), only the detected and quantified pesticides were used.

\subsubsection{Other input sources}

This assessment covers only the public waterworks with known locations and WSAs where at least one pesticide was analysed within the study period. Throughout the workflow, we excluded all pesticide analyses belonging to 95 public waterworks in Denmark, of which 27 could not be geocoded (i.e. no coordinates or address) and 68 had no known WSA. The majority of the first group were supply network locations, which were registered incorrectly as separate waterworks. Changes in the water supply structure could explain why some waterworks had no known WSA - all new waterworks that have become operational after 2014 would not be in the WSA dataset by Schullehner and Hansen (2014). Additionally, changes may have occurred in the supply network of some of the waterworks, but evaluating such changes is beyond the scope of this article. An updated version of the WSA dataset is currently under preparation.
Some of the households included in this study may use private wells for potable water. Approximately 3\% of Danish households use a private well as their source of drinking water (Schullehner et al. 2017). We did not evaluate exposure to pesticides from private wells, since monitoring for drinking-water quality, especially for pesticides, is very limited for these private sources of water supply. However, private wells are known to often have significantly worse water quality than public supplies. In a regional study, carried out in 2000, 35\% of 628 sampled private wells in Denmark had pesticide concentrations $>0.1$ $\mu \mathrm{g} / \mathrm{L}$ (Brüsch et al. 2004). Additionally, $22 \%$ of these wells violated the DWQS for nitrate $(50 \mathrm{mg} / \mathrm{L})$ and $48 \%$ violated the DWQS for microbiological contamination (Brüsch et al. 2004). In a nationwide Danish study, it was estimated that up to $30 \%$ of private wells violated the drinking-water standard for nitrate in the period 1978-2012 (Schullehner et al. 2017). Therefore, we are likely underestimating the percent of households where pesticide levels exceed the DWQS.

Our status assessment and exposure estimation were performed for four general qualitative classes because of limitations in the pesticide dataset. Care must be taken not to over interpret results. For the status assessment at waterworks, one analysis for an individual pesticide exceeding the DWQS within the selected periods would classify the waterworks as 'exceeding DWQS'. Similarly, if one waterworks within a WSA had at least one exceedance in the respective period, all households in that area would be classified as exposed to concentrations exceeding the DWQS. Therefore, we are likely overestimating some of the exposure for WSAs with multiple waterworks. Our assumptions correspond to a worst-case scenario which is in line with deterministic approaches for estimating exposure to pesticides (Ferrier et al. 2002). To quantify this potential overestimation, we categorise the households potentially exposed to $>0.1 \mu \mathrm{g} / \mathrm{l}$ in three groups based on the percentage of waterworks that exceed the DWQS in the WSA (Fig. 8; Table SM-5 in Supplementary File S1). In the first group, where $100 \%$ of the waterworks in a WSA exceeded DWQS, the percent of households potentially exposed to pesticides $>0.1 \mu \mathrm{g} / \mathrm{l}$ is 5.1\% (2002-2019) and 4.5\% (2015-2019). In the second group, where $\geq 50 \%$ of the waterworks in a WSA exceeded DWQS, these percentages are 8.7\% (2002-2019) and 7.1\% (2015-2019). The third group is the most uncertain group, where $<50 \%$ of the waterworks in a WSA exceeded the DWQS. This corresponds to 10.2\% (2002-2019) and $4.2 \%$ (2015-2019) of households. In most of these WSAs, however, the other waterworks contained detected pesticides $(0.03-0.10 \mu \mathrm{g} / \mathrm{l})$. In our study, we were not able to calculate exposure with higher spatial resolution without knowing more about the distribution patterns in the supply system within the WSA. 
Households (\%) potentially exposed to pesticides $>0.1 \mu \mathrm{g} / \mathrm{l}$ by WSA type

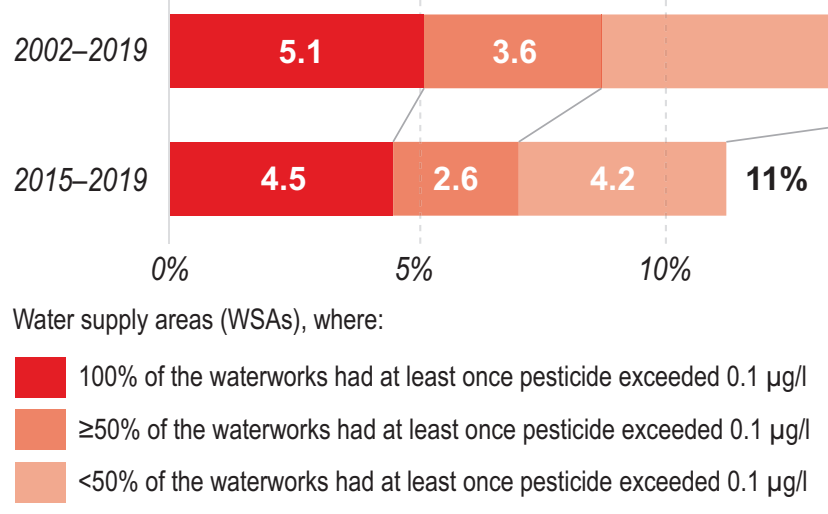

Our assessment provides a first overview on the state of Danish treated drinking water and the potential exposure at household level based on the selected qualitative exposure classes. More detailed assessments on the level of individual consumers can be achieved by epidemiological studies exploring the potential association between exposure to pesticides from drinking water and various health outcomes.

\section{Conclusions and perspectives}

Our study provides a national assessment of pesticide status of Danish drinking water supplied by public waterworks and an estimation of household exposure to pesticides from drinking water. The national groundwater assessment and the Danish EPA mass screening have already provided evidence that pesticide pollution of Danish groundwater is widespread and not only an issue of local importance. Our results compliment these findings and quantify the status based on the treated drinking water supplied to the Danish population. We found that:

1. $0.5 \%(n=4925)$ of the individual analyses of treated drinking water contained a quantified pesticide $(\geq 0.03 \mu \mathrm{g} / \mathrm{l})$ and of those $16 \%(n=793)$ exceeded the DWQS.

2. BAM had the most complete spatiotemporal coverage, and DPC had the highest measured concentration. Together with DMS, these three pesticides had the highest number of DWQS exceedances in the study period.

3. 9\% (2002-2019) and 7\% (2015-2019) of the waterworks had an exceedance of the DWQS $(>0.1 \mu \mathrm{g} / \mathrm{l})$. In addition, $20 \%$ and $17 \%$ of waterworks contained pesticides with lower concentrations (0.03-0.10 $\mu \mathrm{g} / \mathrm{l})$ for the two respective periods. These results compare well with the raw groundwater status reported by Thorling et al. (2019).

4. 19\% (2002-2019) and 11\% (2015-2019) of Danish households were potentially exposed to pesticides
Fig. 8 Uncertainty in the estimate of households (\%) exposed to pesticides exceeding the DWQS $(0.1$ $\mu \mathrm{g} / \mathrm{l})$.
$>0.1 \mu \mathrm{g} / \mathrm{I}$. In addition, 37 and 30\% were potentially exposed to lower concentrations (0.03-0.10 $\mu \mathrm{g} / \mathrm{l})$ for the two periods, respectively.

5. One-third of the pesticides with established WHO guideline values (protective against health effects from a lifetime exposure) were found, but all were lower than the guideline values.

We demonstrate that the central registration of all chemical analyses of Danish drinking water in the Jupiter database allows us to assess the current and past spatiotemporal status of Danish drinking water. While the open access to Jupiter is a major advantage, care should be taken as the data structure is highly heterogeneous regarding sampling frequency and pesticides analysed. A strength of our study is that we implemented and documented extensive data pre-processing procedures in detail, allowing reproducibility and further informed use of the dataset. We have also included a comprehensive account of different methodological limitations, which are important for future epidemiological studies.

\section{Acknowledgements}

We thank Ingelise M. Balling and Lærke Thorling for providing comments and suggestions on the data quality control and filtering procedure (QC1). We are also thankful to Lærke Thorling and Anders R. Johnsen, whose thoughtful comments on an earlier version of this manuscript helped us clarify and sharpen some of the findings. We are grateful to the two anonymous reviewers for providing constructive and detailed reviews, which pushed us to perform additional uncertainty analysis and to restructure the manuscript for clarity.

\section{Additional information}

Funding statement

This work was funded under the project 'Geographical clustering of leukaemia and multiple myeloma and association with pesticides in ground water' by the Karen Elise Jensen Fond (2017-2021).

Author contributions

DV contributed to the conceptualisation, data curation, formal analysis, methodology, visualisation and writing (original draft). JS contributed to the conceptualisation, data curation, methodology, validation and 
writing (review and editing). CS contributed to the conceptualisation, validation and writing (review and editing). KW contributed to the conceptualisation, validation and writing (review and editing). AKE contributed to the conceptualisation, funding acquisition, project administration and writing (review and editing). $\mathrm{BH}$ contributed to the conceptualisation, supervision, methodology, project administration and writing (review and editing).

\section{Additional files}

Two supplementary files are available at $h$ ttps://doi.org/10.22008/ FK2/7HHX73.

\section{References}

Antweiler, R.C. 2015: Evaluation of statistical treatments of left-censored environmental data using coincident uncensored data sets. II. Group comparisons. Environmental Science and Technology 49, 1343913446. https://doi.org/10.1021/acs.est.5b02385

Antweiler, R.C. \& Taylor, H.E. 2008: Evaluation of statistical treatments of left-censored environmental data using coincident uncensored data sets: I. Summary statistics. Environmental Science and Technology 42, 3732-3738. https://doi.org/10.1021/es071301c

Bexfield, L.M., Belitz, K., Lindsey, B.D., Toccalino, P.L. \& Nowell, L.H. 2021: Pesticides and pesticide degradates in groundwater used for public supply across the United States: occurrence and human-health context. Environmental Science and Technology 55, 362-372. https://doi. org/10.1021/acs.est.0c05793

Bichel hovedudvalget. 1999. Bichel-Udvalget, Udvalget til vurdering af de samlede konsekvenser af en hel eller delvis afvikling af pesticidanvendelsen (In Danish only). Copenhagen: Miljø og Energiministeriet. https://mst.dk/service/publikationer/publikationsarkiv/1999/maj/rapport-fra-hovedudvalget/ (accessed February 2021)

Bourguignon, D. 2016: The precautionary principle: definitions, applications and governance: in-depth analysis. European Parliament, Directorate-General for Parliamentary Research Services. Luxembourg: Publications Office of the European Union. http://bookshop. europa.eu/uri?target=EUB:NOTICE:QA0115945:EN:HTML (accessed July 2020)

Brüsch, W., Stockmarr, J., Kelstrup, N., von Platen-Hallermund, F., Rosenberg, P. 2004: Pesticidforurenet vand i små vandforsyninger (GEUS Rapport No. 2004/9). (In Danish only). Copenhagen: Geological Survey of Denmark and Greenland.

Casida, J.E. 2009: Pest toxicology: the primary mechanisms of pesticide action. Chemical Research in Toxicology 22, 609-619. https://doi. org/10.1021/tx8004949

Commission of the European Communities. 2009: Commission Directive 2009/90/EC of 31 July 2009 laying down, pursuant to Directive 2000/60/EC of the European Parliament and of the Council, technical specifications for chemical analysis and monitoring of water status. Official Journal of the European Union L 201 1.8.2009, 36. http://data. europa.eu/eli/dir/2009/90/oj (accessed July 2020)

Council of the European Union. 2015: Council Directive 98/83/EC of 3 November 1998 on the quality of water intended for human consumption. Official Journal of the European Union L 330 5.12.1998, 32. http://data.europa.eu/eli/dir/1998/83/2015-10-27 (accessed June 2020)

Dolan, T., Howsam, P., Parsons, D.J. \& Whelan, M.J. 2013: Is the EU drinking water directive standard for pesticides in drinking water consistent with the precautionary principle? Environmental Science and Technology 47, 4999-5006. https://doi.org/10.1021/es304955g

Dowle, M. \& Srinivasan, A. 2019: data.table: extension of 'data.frame'. R package version 1.12.2. https://CRAN.R-project.org/package=data.table

European Commission. 2018. Proposal for a Directive of the European Parliament and of the Council on the quality of water intended for human consumption (recast). COM/2017/0753 final - 2017/0332 (COD). https://eur-lex.europa.eu/legal-content/EN/ALL/?uri=CELEX:52017PC0753 (accessed February 2021)

Food and Agriculture Organization \& World Health Organization. 2019: Detoxifying agriculture and health from highly hazardous pesticides a call for action. Rome: Food and Agriculture Organization. https://www. who.int/neglected_diseases/vector_ecology/resources/9789241517065/ en/ (accessed February 2021)
Fenner, K., Canonica, S., Wackett, L.P., Elsner, M. 2013: Evaluating pesticide degradation in the environment: blind spots and emerging opportunities. Science 341, 752-758. https://doi.org/10.1126/science.1236281

Ferrier, H., Nieuwenhuijsen, M., Boobis, A., Elliott, P. 2002: Current knowledge and recent developments in consumer exposure assessment of pesticides: a UK perspective. Food Additives and Contaminants 19, 837-852. https://doi.org/10.1080/02652030210156322

Hansen, C.T., Ritz, C., Gerhard, D., Jensen, J.E., Streibig, J.C. 2016: Reply to: comments on the paper: re-evaluation of groundwater monitoring data for glyphosate and bentazone by taking detection limits into account. Science of The Total Environment 557-558, 916. https://doi. org/10.1016/j.scitotenv.2016.03.116

Hansen, C.T., Ritz, C., Gerhard, D., Jensen, J.E., Streibig, J.C. 2015: Re-evaluation of groundwater monitoring data for glyphosate and bentazone by taking detection limits into account. Science of The Total Environment 536, 68-71. https://doi.org/10.1016/j.scitotenv.2015.07.047

Helsel, D.R. 2005: More than obvious: better methods for interpretting nondetect data. Environmental Science and Technology 39, 419A-423A. https://doi.org/10.1021/es053368a

Inkscape Project. 2019: Inkscape 0.92.4 https://inkscape.org (accessed February 2021)

Johnsen, A.R., Thorling, L., Helsel, D.R., Larsen, F. 2016: Comments on the article: re-evaluation of groundwater monitoring data for glyphosate and bentazone by taking detection limits into account. Science of The Total Environment 557-558, 914-915. https://doi.org/10.1016/j. scitotenv.2016.02.130

Kim, K.-H., Kabir, E., Jahan, S.A. 2017: Exposure to pesticides and the associated human health effects. Science of The Total Environment 575, 525-535. https://doi.org/10.1016/j.scitotenv.2016.09.009

Kohler, H.-R. \& Triebskorn, R. 2013: Wildlife ecotoxicology of pesticides: can we track effects to the population level and beyond? Science 341, 759-765. https://doi.org/10.1126/science. 1237591

Li, Z. \& Jennings, A. 2018.: Global variations in pesticide regulations and health risk assessment of maximum concentration levels in drinking water. Journal of Environmental Management 212, 384-394. https:// doi.org/10.1016/j.jenvman.2017.12.083

Mathiesen, S.R. 2020: Massescreening viser ulovlige sprøjtemidler i grundvandet (in Danish only). Maskinbladet. https://www.maskinbladet.dk/artikel/66875-massescreening-viser-ulovlige-sprojtemidler-i-grundvandet (accessed April 2020)

Miljøstyrelsen. 2020a. Kortlægning af tilladelser til videregående vandbehandling 2012 - 2019 (in Danish only). Government memo. Odense: Miljøstyrelsen. https://mst.dk/media/203285/resultat-af-kortlaegningen-2012-2019-090720.pdf (accessed January 2021)

Miljøstyrelsen. 2020b. Vejledning om indberetning og godkendelse af vandforsyningsdata I Jupiterdatabasen 'Jupitervejledning'. Vejledning 116 (in Danish only). Government report. Odense: Miljøstyrelsen. https://mst.dk/natur-vand/vand-i-hverdagen/drikkevand/ indberetning-og-godkendelse-af-vandforsyningsdata-jupitervejledningen/ (accessed July 2020)

Mohaupt, V. et al. 2020: Pesticides in European rivers, lakes and groundwaters - data assessment (ETC/ICM Technical Report No. 1/2020). Magdeburg: European Topic on Inland, Coastal and Marine waters (ETC/ICM). https://www.eionet.europa.eu/etcs/etc-icm/products/etc-icmreport-1-2020-pesticides-in-european-rivers-lakes-and-groundwaters-data-assessment (accessed November 2020)

Naturstyrelsen. 2012. Videregående vandbehandling: Kortlægning af kommunernes tilladelser (in Danish only). Government report. Copenhagen: Naturstyrelsen. https://naturstyrelsen.dk/media/nst/ Attachments/Videregende_vandbehandling_2012.pdf (accessed July 2020)

Pedersen, M.G. 2018: Geocoding of Danish addresses from the Residence Database version 2016, 1-7. Institutional report. Aarhus: Centre for Integrated Register-Based Research. https://cirrau.au.dk/ fileadmin/cirrau/Documents/ophold2016b.pdf (accessed July 2020)

QGIS Development Team. 2019: QGIS geographic information system. Open Source Geospatial Foundation Project. http://qgis. osgeo.org

R Core Team. 2019: R: A language and environment for statistical computing. R v. 4.0.2 Foundation for Statistical Computing, Vienna, Austria. https://www.R-project.org/ 
Rosenstock, L. 1991: Chronic central nervous system effects of acute organophosphate pesticide intoxication. The Lancet 338, 223-227. https://doi.org/10.1016/0140-6736(91)90356-T

RStudio Team. 2018: RStudio: Integrated development for R. RStudio Inc., Boston, MA, USA. http://www.rstudio.com/

Schullehner, J. \& Hansen, B. 2014: Nitrate exposure from drinking water in Denmark over the last 35 years. Environmental Research Letters 9, 095001. https://doi.org/10.1088/1748-9326/9/9/095001

Schullehner, J., Jensen, N.L., Thygesen, M., Hansen, B., Sigsgaard, T. 2017: Drinking water nitrate estimation at household-level in Danish population-based long-term epidemiologic studies. Journal of Geochemical Exploration 183, 178-186. https://doi.org/10.1016/j.gexplo.2017.03.006 Sjerps, R.M.A., Kooij, P.J.F., van Loon, A., Van Wezel, A.P. 2019: Occurrence of pesticides in Dutch drinking water sources. Chemosphere 235, 510-518. https://doi.org/10.1016/j.chemosphere.2019.06.207

Stehle, S. \& Schulz, R. 2015: Agricultural insecticides threaten surface waters at the global scale. Proceedings of the National Acadamy of Sciences 112, 5750-5755. https://doi.org/10.1073/pnas.1500232112

Stow, C.A., Webster, K.E., Wagner, T., Lottig, N., Soranno, P.A., Cha, Y. 2018: Small values in big data: the continuing need for appropriate metadata. Ecological Informatics 45, 26-30. https://doi.org/10.1016/j. ecoinf.2018.03.002

Thorling, L., Ditlefsen, C., Ernstsen, V., Hansen, B., Johnsen, A.R., Troldborg, L. 2019: Grundvandovervågning. Status og udvikling 1989 2018 (in Danish only). Institutional report. Copenhagen: Geological Survey of Denmark and Greenland.
Voutchkova, D., Schullehner, J., Knudsen, N., Jørgensen, L., Ersbøll, A., Kristiansen, S., Hansen, B. 2015: Exposure to selected geogenic trace elements (I, Li, and $\mathrm{Sr}$ ) from drinking water in Denmark. Geosciences 5, 45-66. https://doi.org/10.3390/geosciences5010045

Wickham, H. 2016: ggplot2: Elegant graphics for data analysis. New York, NY: Springer-Verlag. https://ggplot2.tidyverse.org

Wickham, H., François, R., Henry, L. \& Müller, K. 2019: dplyr: a grammar of data manipulation. $\mathrm{R}$ package version 0.8.3. https://CRAN.R-project. org/package $=$ dplyr

Wickham, H. \& Henry, L. 2019: tidyr: Tidy Messy Data. R package version 1.0.0. https://CRAN.R-project.org/package=tidyr

World Health Organization. 2011: Guidelines for drinking-water quality, 4th edition. Geneva: World Health Organization. https://www.who.int/ publications/i/item/9789241548151 (accessed January 2020)

World Health Organization. 2017: Guidelines for drinking-water quality, 4th edition, incorporating the first addendum. Geneva: World Health Organization. https://www.who.int/publications/i/item/9789241549950 (accessed July 2020)

World Health Organization. 2019a. Preventing disease through healthy environments. Exposure to highly hazardous pesticides: major public health concern. Geneva: World Health Organization. https://apps.who. int/iris/handle/10665/329501 (accessed July 2020)

World Health Organization. 2019b: WHO recommended classification of pesticides by hazard and guidelines to classification, revision 2019. Geneva: World Health Organization. https://apps.who.int/iris/handle/10665/329501 (accessed July 2020) 